\title{
Electromagnetic and Mechanical Characteristics Analysis of a Flat-Type Vertical-Gap Passive Magnetic Levitation Vibration Isolator
}

\author{
Baoquan Kou, Yiheng Zhou, Xiaobao Yang, Feng Xing, and He Zhang \\ School of Electrical Engineering and Automation, Harbin Institute of Technology, Harbin, China \\ Correspondence should be addressed to Baoquan Kou; koubq@hit.edu.cn
}

Received 23 August 2016; Revised 22 November 2016; Accepted 5 December 2016

Academic Editor: Lu Chen

Copyright (C) 2016 Baoquan Kou et al. This is an open access article distributed under the Creative Commons Attribution License, which permits unrestricted use, distribution, and reproduction in any medium, provided the original work is properly cited.

\begin{abstract}
In this paper, we describe a flat-type vertical-gap passive magnetic levitation vibration isolator (FVPMLVI) for active vibration isolation system (AVIS). A dual-stator scheme and a special stator magnet array are adopted in the proposed FVPMLVI, which has the effect of decreasing its natural frequency, and this enhances the vibration isolation capability of the FVPMLVI. The structure, operating principle, analytical model, and electromagnetic and mechanical characteristics of the FVPMLVI are investigated. The relationship between the force characteristics (levitation force, horizontal force, force ripple, and force density) and major structural parameters (width and thickness of stator and mover magnets) is analyzed by finite element method. The experiment result is in good agreement with the theoretical analysis.
\end{abstract}

\section{Introduction}

Active vibration isolation system (AVIS), which integrates actuators with passive gravity compensation devices, can effectively improve the accuracy of measuring and machining equipment. Therefore, active vibration isolation systems have been widely used in many advanced industrial applications such as microscopy and lithography. As an important component of active vibration isolation system, the passive gravity compensation device plays the role of supporting and vibration isolation, and such characteristics like high force density and low natural frequency are required. More importantly, lower natural frequency leads to wider vibration isolation bandwidth and lower vibration transmissibility. Owing to the advantage of low natural frequency, air springs are widely adopted as passive gravity compensation devices in many active vibration isolation systems. However, some ultraprecision equipment must operate in a moderate vacuum, for example, extreme ultraviolet lithography [1]. It is difficult for air springs to be applied in vacuum environment, because air springs need compressed gas [2]. To solve the problem, passive magnetic levitation vibration isolator is used as a substitute for air spring.
Passive magnetic levitation vibration isolators generate levitation force by interaction between magnets and have drew increased interest in recent years due to their feature of vacuum compatibility. Puppin and Fratello proposed a vibration isolation apparatus composed of four passive magnetic levitation vibration isolators in 2002; its natural frequency is $6.1 \mathrm{~Hz}$ at a load of $4 \mathrm{~kg}$ and $5.8 \mathrm{~Hz}$ at a load of $15 \mathrm{~kg}$ [2]. Zhu et al. proposed a passive magnetic levitation vibration isolator composed of ring-shaped permanent magnets; they studied its axial force and stiffness characteristics, and its natural frequency is about $6 \mathrm{~Hz}$ [3]. Robertson et al. proposed a multipole array passive magnetic levitation vibration isolator [4] and studied the design method of passive magnetic levitation vibration isolators $[5,6]$. Lomonova et al. also studied the design method of passive magnetic levitation vibration isolators [7-9]. Zhu et al. proposed a vibration isolator composed of permanent magnets and rubber ligaments, they reduced the natural frequency of the vibration isolator by about $50 \%$, and its lowest natural frequency is $2.75 \mathrm{~Hz}$ [10]. $\mathrm{Xu}$ et al. designed a vibration isolation system composed of permanent magnets and a coil spring [11]. Wu et al. designed a vibration isolator composed of three cuboidal magnets and a coil spring; its natural frequency is reduced from $10.45 \mathrm{~Hz}$ to 


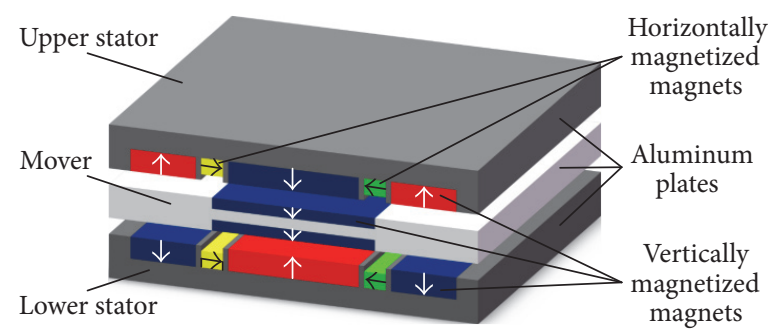

FIGURE 1: The structure of flat-type vertical-gap passive magnetic levitation vibration isolator.

$4.96 \mathrm{~Hz}$ at a load of $2.29 \mathrm{~kg}$ [12]. Shin analyzed the maximum vibration transmissibility of a vibration isolator composed of four magnets and two coil springs [13]. Zheng et al. designed a vibration isolator composed of ring-shaped magnets and a coil spring; its natural frequency is reduced from $9.0 \mathrm{~Hz}$ to $5.8 \mathrm{~Hz}$ [14]. As mentioned above, most published works about this kind of device show higher natural frequency than air springs, which is adverse for vibration isolation.

Herein, we propose a flat-type vertical-gap passive magnetic levitation vibration isolator (FVPMLVI) that features vacuum compatibility, low natural frequency, and no mechanical contact. A dual-stator scheme is adopted in the proposed FVPMLVI to decrease its natural frequency. This paper focuses on the operation principle and characteristics analysis of the FVPMLVI and provides useful advices for its application. This paper is organized as follows. In Section 2, the structure and operation principle of the FVPMLVI are introduced. In Section 3, the analytical model of the FVPMLVI is established. In Section 4, the electromagnetic and mechanical characteristics of the FVPMLVI are studied in detail by finite element method, and the force characteristics experiment is carried out. A summary is included in Section 5.

\section{Structure and Operating Principle}

The proposed flat-type vertical-gap passive magnetic levitation vibration isolator consists of three components, that is, upper stator, mover, and lower stator, as shown in Figure 1. The mover consists of an aluminum plate and two vertically magnetized magnets. Both the upper and the lower stators consist of an aluminum plate, three vertically magnetized magnets, and two horizontally magnetized magnets. The magnetization direction of the magnets is shown as arrows in Figures 1 and 2 . The major structural parameters of flat-type vertical-gap passive magnetic levitation vibration isolator are shown in Figure 2.

The flat-type vertical-gap passive magnetic levitation vibration isolator generates levitation force by the attraction and repulsion between stator and mover magnets. The mover is suspended above the stator by the magnetic force between stator and mover magnets. When the mover moves relative to the stators along the vertical direction, the upper stator and mover generate attractive force with negative stiffness and the lower stator and mover generate repulsive force with positive stiffness; thus the total levitation force is near-constant. When

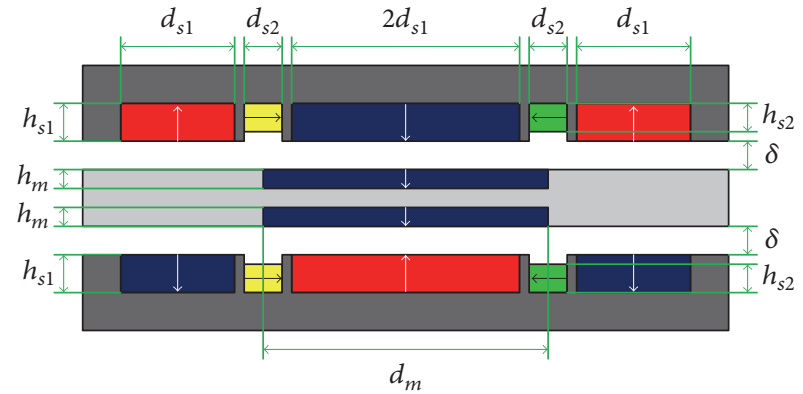

FIGURE 2: The major structural parameters of flat-type vertical-gap passive magnetic levitation vibration isolator and the magnetization direction of magnets.

the mover moves relative to the stators along the horizontal direction, the total levitation force generated by magnets on the left side and the right side is also near-constant. Through adopting the dual-stator structure and inserting horizontally magnetized magnets, the flat-type vertical-gap passive magnetic levitation vibration isolator can generate nearconstant levitation force and near-zero stiffness in six-degree of freedom stroke, which is useful for improving the vibration isolation performance of active vibration isolation system.

The proposed flat-type vertical-gap passive magnetic levitation vibration isolator has two advantages: (1) using parallel magnetized cubic magnets; the vertically and horizontally magnetized magnets used in FVPMLVI are parallel magnetized cubic magnets; compared with radially magnetized magnets used in many vibration isolators, the parallel magnetized cubic magnets have advantages of simple structure, good manufacturability, and low cost; and (2) low natural frequency. The natural frequency of FVPMLVI can be decreased effectively by adopting dual-stator scheme and special stator magnet array.

\section{Analytical Model}

The force generated by flat-type vertical-gap passive magnetic levitation vibration isolator can be calculated by superposition of magnetic force between each two magnets (one of the two magnets is on the stator and another is on the mover). The magnetic force between magnets can be calculated by the equivalent charge model. The equivalent charge model of flat-type vertical-gap passive magnetic levitation vibration 


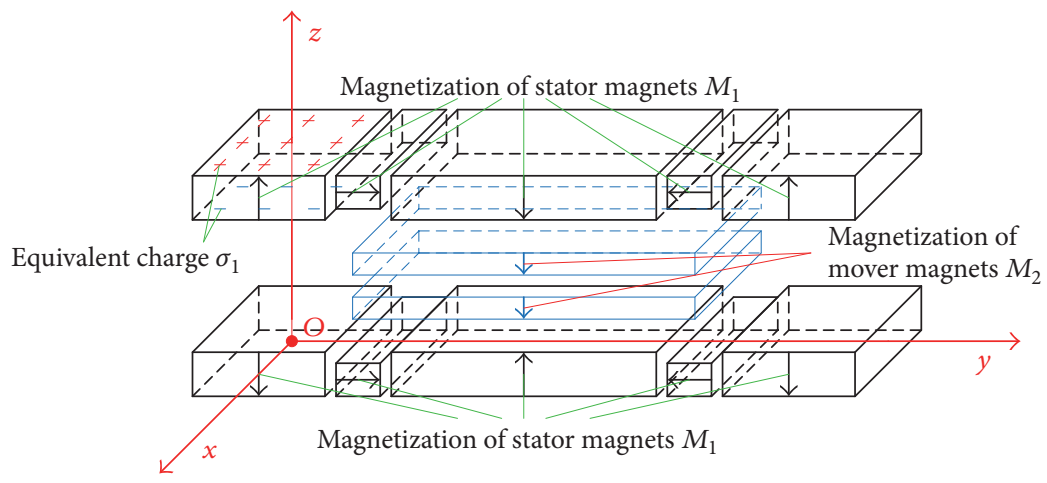

FIGURE 3: The equivalent charge model of flat-type vertical-gap passive magnetic levitation vibration isolator.

isolator is shown in Figure 3. The cuboidal magnets are equivalent to a series of charged rectangular surface.

According to the work of Allag et al. [15], the magnetic force between two magnets with parallel and perpendicular magnetization can be expressed as $F_{\text {parallel }}$ and $F_{\text {perpendicular, }}$, separately. Since there are 6 vertically magnetized magnets on the stators and 2 vertically magnetized magnets on the mover, thus there are $6 \times 2$ pairs of magnets with parallel magnetization. Similarly, there are 4 horizontally magnetized magnets on the stators; thus there are $4 \times 2$ pairs of magnets with perpendicular magnetization. Then, the force of the flat-type vertical-gap passive magnetic levitation vibration isolator is given by

$$
\begin{aligned}
F & =\sum_{m=1}^{6 \times 2} F_{\text {parallel }}+\sum_{n=1}^{4 \times 2} F_{\text {perpendicular }} \\
& =\sum_{m=1}^{12} F_{\text {parallel }}+\sum_{n=1}^{8} F_{\text {perpendicular }}
\end{aligned}
$$

where $F_{\text {parallel }}$ is the magnetic force between two magnets with parallel magnetization and $F_{\text {perpendicular }}$ is the magnetic force between two magnets with perpendicular magnetization.

Thus the stiffness $k$ and natural frequency $f$ of the flat-type vertical-gap passive magnetic levitation vibration isolator can be expressed as (2) and (3).

$$
k=\frac{d F}{d s},
$$

where $k$ is the stiffness, $d F$ is the variation of force, and $d s$ is the displacement.

$$
f=\frac{1}{2 \pi} \sqrt{\frac{k}{m}}=\frac{\sqrt{g}}{2 \pi} \sqrt{\frac{d F / F}{d s}},
$$

where $f$ is the natural frequency, $m$ is the total mass of mover, and load $g$ is the gravitational acceleration.

As shown in (3), compared to stiffness $k$, the force ripple within unit displacement $d F / F / d s$ is a better indicator which can reflect the vibration isolator's vibration isolation performance, because the natural frequency $f$ is directly related to vibration isolation ability. Therefore, force ripple is analyzed instead of stiffness in the next section.

\section{Electromagnetic and Mechanical Characteristics Analysis}

In order to provide useful advice for application, the electromagnetic and mechanical characteristics of FVPMLVI such as levitation force, horizontal force, force ripple, and force density are analyzed in this section. Firstly, the force characteristics of FVPMLVI which varied with mover position are studied, and the principle of reducing force ripple is analyzed. Then, the influence of major structural parameters on the device performance like levitation force, force density, and force ripple is studied. At last, the force characteristics of a FVPMLVI prototype is tested to validate the analysis.

4.1. Force Characteristics Varied with Mover Position and Principle of Reducing Force Ripple. When the mover moves relative to the stators, the magnetic force generated by interaction between magnets will change inevitably. The finite element method is used here to analyze the vibration of the force. The mesh result and magnetic field distribution are shown in Figure 4.

When the mover moves relative to the stators along the vertical direction, the levitation force characteristic which varied with vertical motion is shown in Figure 5(a). For a certain horizontal position $y$, with the increase in vertical position $z$, the levitation force first decreases and then increases. The minimum levitation force occurs when $z$ is about $0.4 \mathrm{~mm}$. When the mover moves relative to the stators along the horizontal direction, the levitation force characteristic which varied with horizontal motion is shown in Figure 5(b). For a certain vertical position $z$, with the increase in horizontal position $y$, the levitation force first increases and then decreases when $z$ is larger than $-0.6 \mathrm{~mm}$. The maximum levitation force occurs when $x$ is $0.0 \mathrm{~mm}$. It should be noted that the vertical position $z=0 \mathrm{~mm}$ means the position $1 \mathrm{~mm}$ below the center of FVPMLVI.

When the mover moves relative to the stators along the vertical direction, the horizontal force characteristic which varied with vertical motion is shown in Figure 6(a). For a certain horizontal position $y$, with the increase in vertical position $z$, the horizontal force decreases. When the mover moves relative to the stators along the horizontal direction, the horizontal force characteristic which varied with horizontal motion is shown in Figure 6(b). For a certain vertical 


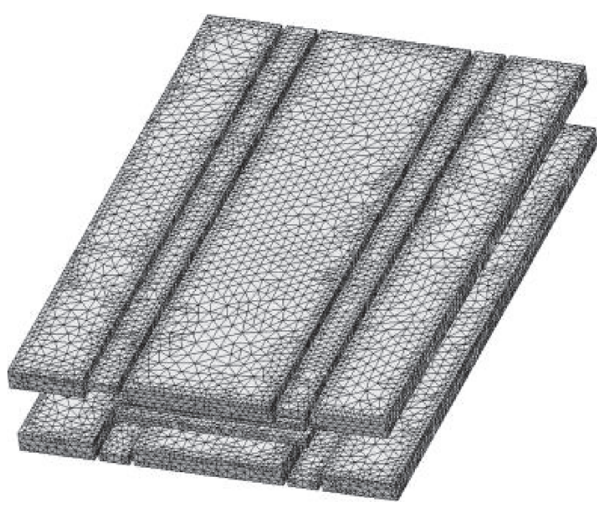

(a)

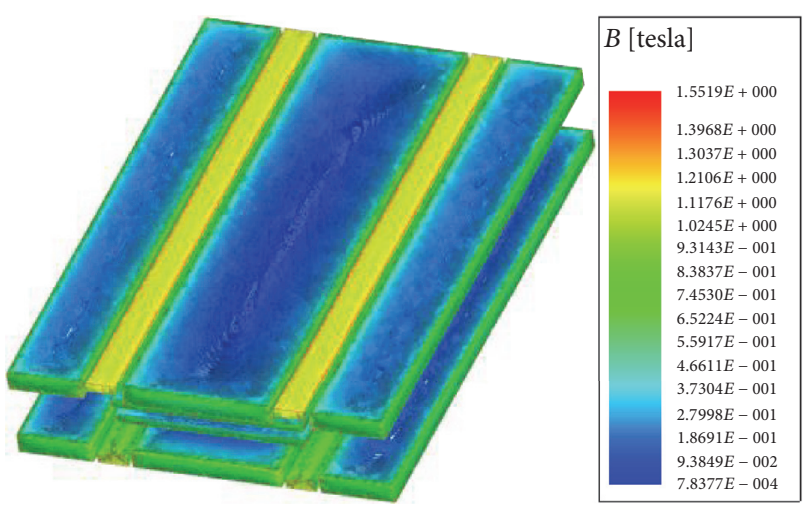

(b)

FIgURE 4: The finite element model of FVPMLVI: (a) mesh result; (b) magnetic field distribution.

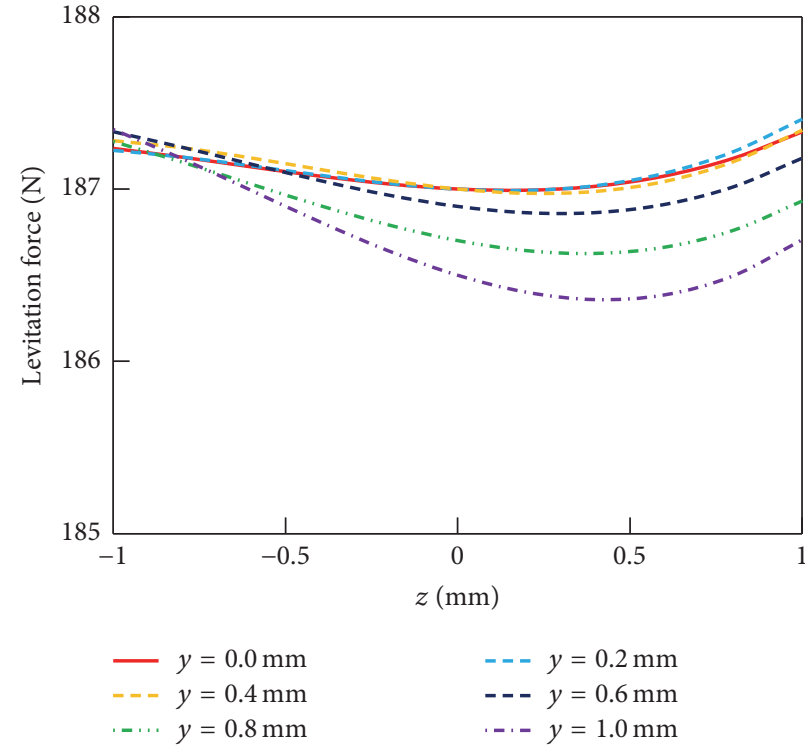

(a)

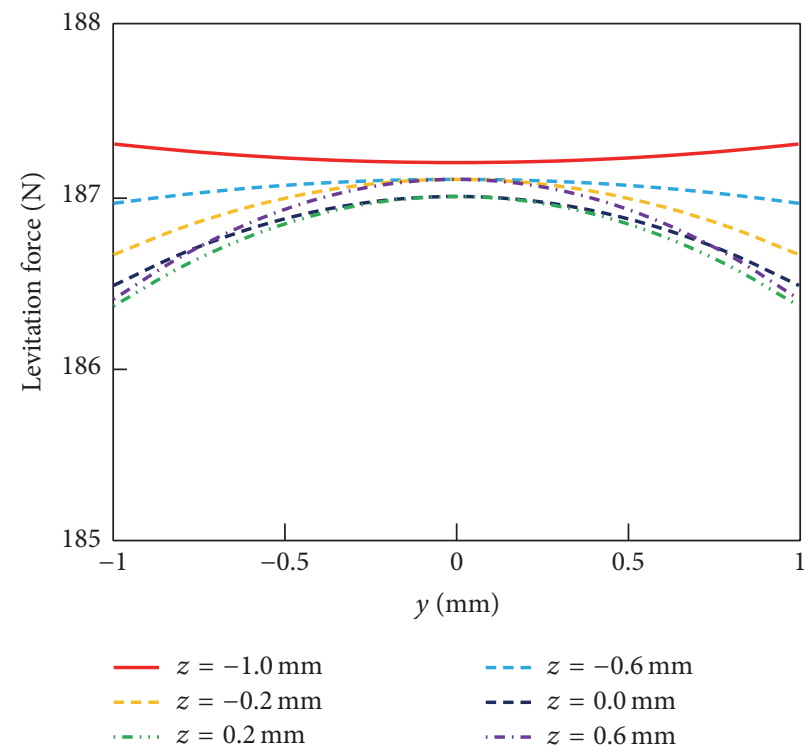

(b)

FIGURE 5: Levitation force characteristics versus motion of mover: (a) vertical motion $z$; (b) horizontal motion $y$.

position $z$, with the increase in horizontal position $y$, the levitation force is approximately proportional to horizontal position $x$. As shown in Figures 5 and 6 , the vibration of levitation force generated by FVPMLVI is not more than $1 \mathrm{~N}$ in the $\pm 1 \mathrm{~mm}$ stroke, and the vibration of horizontal force is not more than $4 \mathrm{~N}$.

The following is the analysis about the role of special stator magnet array and dual-stator scheme. Firstly, the role of special stator magnet array is analyzed. As shown in Figure 7, the stator magnets are divided into three magnet arrays, that is, magnet array $\mathrm{A}$, magnet array $\mathrm{B}$, and magnet array $\mathrm{C}$. The force generated by FVPMLVI is the superposition of magnetic force between these three magnet arrays and mover magnets.

The levitation force characteristics of these three magnet arrays are shown in Figure 8. When the mover moves relative to the stators along the vertical direction, the stiffness of levitation force generated by magnet array A is near-zero, the stiffness of levitation force generated by magnet array $\mathrm{B}$ is negative, and the stiffness of levitation force generated by magnet array $\mathrm{C}$ is positive. When the mover moves relative to the stators along the horizontal direction, the levitation force generated by magnet array A and magnet array B increases when $|y|$ increases, and the levitation force generated by magnet array $\mathrm{C}$ decreases when $|y|$ increases. Thus, a nearconstant levitation force can be obtained by appropriate combination.

The horizontal force characteristics of these three magnet arrays are shown in Figure 9. When the mover moves relative to the stators along the vertical direction, the horizontal force generated by magnet array A and magnet array B decreases when $z$ increases, and the horizontal force generated by magnet array $\mathrm{C}$ increases when $z$ increases. When the mover moves relative to the stators along the horizontal direction, 


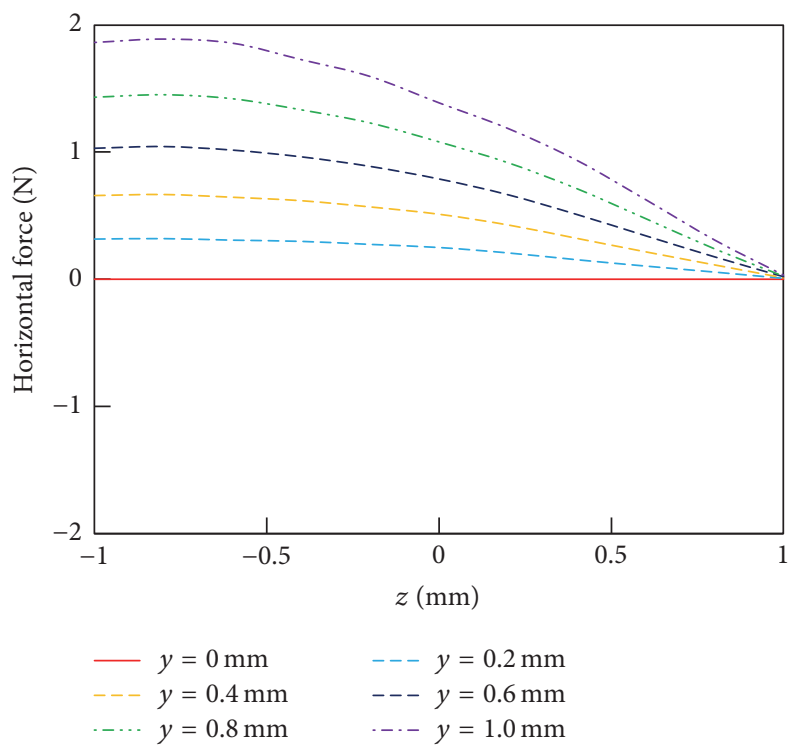

(a)

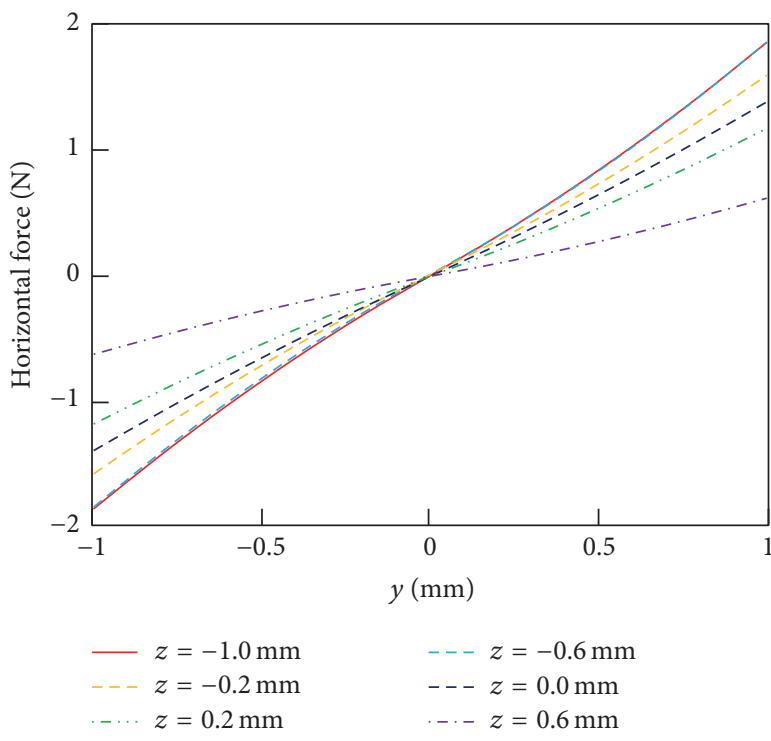

(b)

FIGURE 6: Horizontal force characteristics versus motion of mover: (a) vertical motion $z$; (b) horizontal motion $y$.

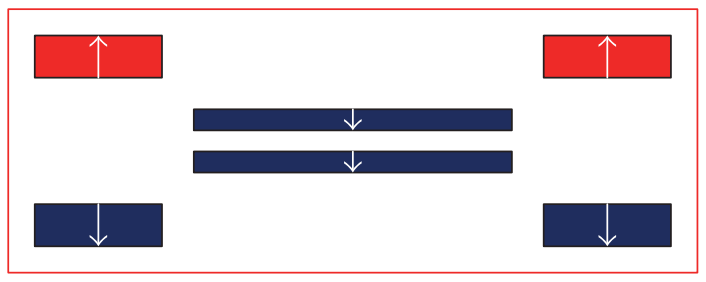

(a)

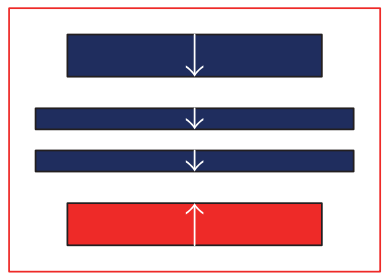

(b)

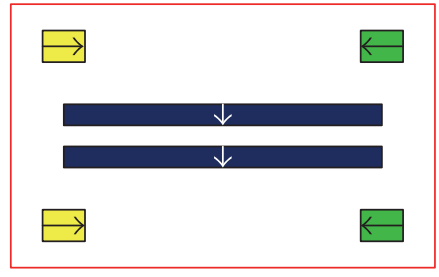

(c)

FIGURE 7: The structure of three magnet arrays: (a) magnet array A; (b) magnet array B; (c) magnet array C.

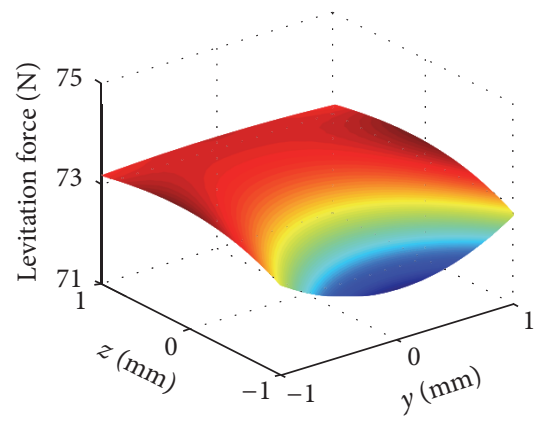

(a)

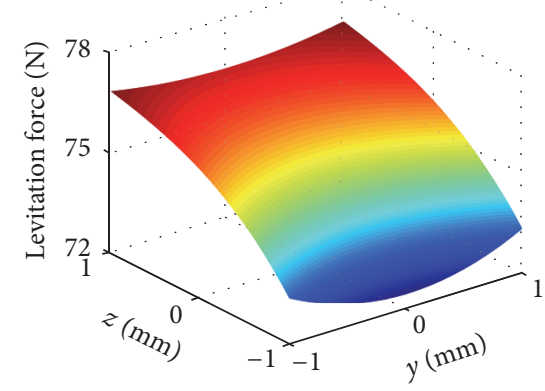

(b)

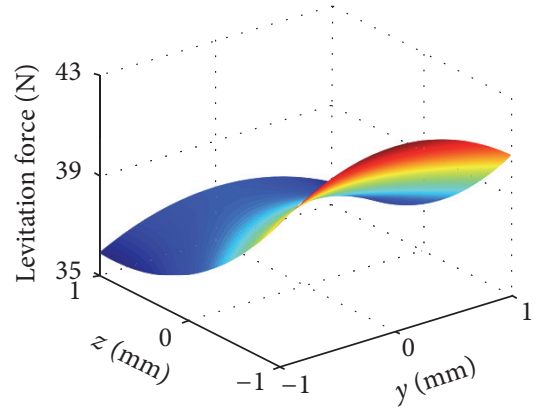

(c)

FIGURE 8: Levitation force characteristics of three magnet arrays: (a) array A; (b) array B; (c) array C.

the stiffness of horizontal force generated by magnet array A and magnet array $\mathrm{B}$ is positive, and the stiffness of levitation force generated by magnet array $\mathrm{C}$ is negative. Thus, a near-zero vertical stiffness can be obtained by appropriate combination. Thus, the special stator magnet array, which is composed of three vertically magnetized magnets and two horizontally magnetized magnets, can effectively decrease the force ripple of FVPMLVI.
Similarly, the role of dual-stator scheme is analyzed. As shown in Figure 10, the stator magnets are divided into two magnet arrays, that is, magnet array D and magnet array E. The force generated by FVPMLVI is the superposition of magnetic force between these two magnet arrays and mover magnets.

The levitation force characteristics of these two magnet arrays are shown in Figure 11. When the mover moves relative 


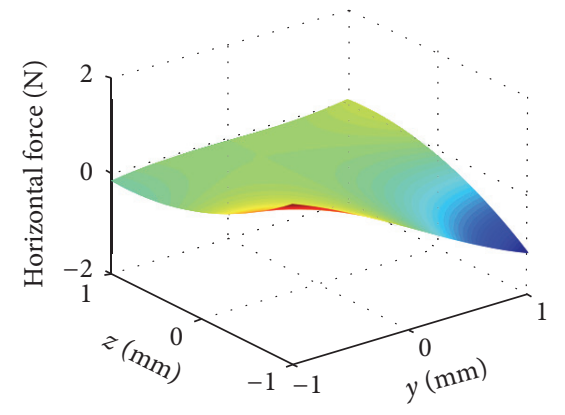

(a)

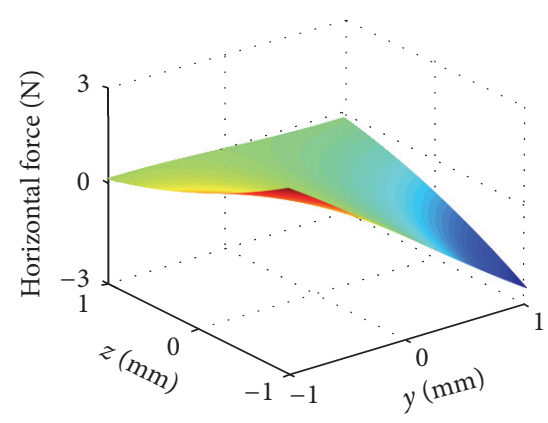

(b)

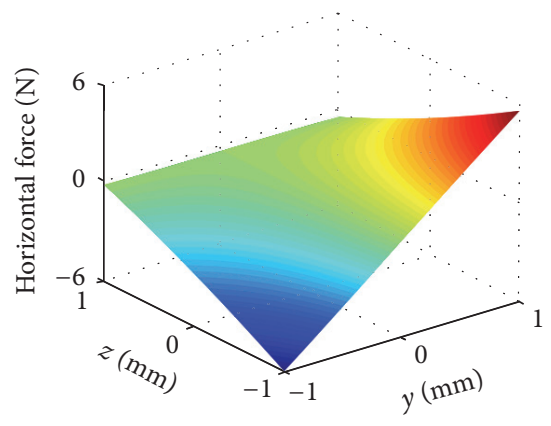

(c)

FIGURE 9: Horizontal force characteristics of three magnet arrays: (a) array A; (b) array B; (c) array C.

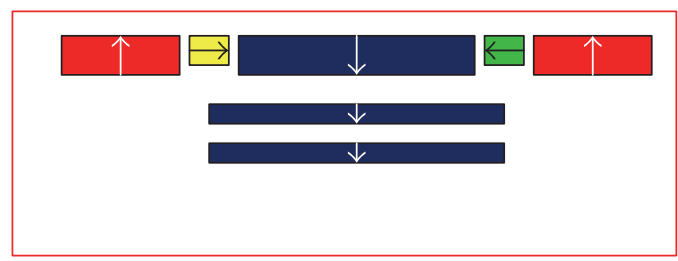

(a)

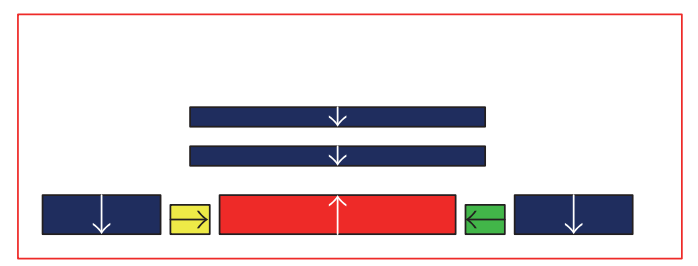

(b)

FIgURE 10: The structure of two magnet arrays: (a) magnetic array D; (b) magnetic array E.

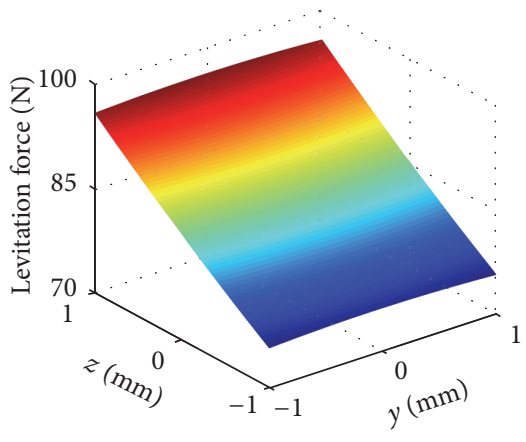

(a)

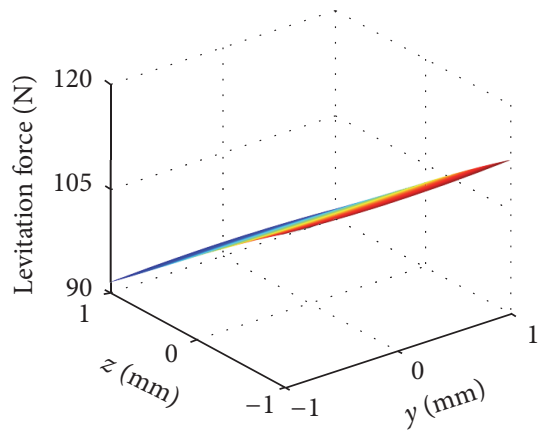

(b)

FIGURE 11: Levitation force characteristics of two magnet arrays: (a) magnetic array D; (b) magnetic array E.

to the stators along the vertical direction, the stiffness of levitation force generated by magnet array $\mathrm{D}$ is negative, and the stiffness of levitation force generated by magnet array $\mathrm{E}$ is positive. Thus, a near-constant levitation force can be obtained by appropriate combination.

The horizontal force characteristics of these three magnet arrays are shown in Figure 12. When the mover moves relative to the stators along the horizontal direction, the stiffness of horizontal force generated by magnet array $\mathrm{D}$ is positive, and the stiffness of levitation force generated by magnet array $\mathrm{E}$ is negative. Thus, a near-zero vertical stiffness can be obtained by appropriate combination.

In conclusion, the natural frequency of FVPMLVI can be decreased effectively by adopting the dual-stator scheme and special stator magnet array, and the structural parameters of magnets should be carefully designed because the force characteristics of FVPMLVI depend on the combination of force characteristics of several magnet arrays.

4.2. Influence of Major Structural Parameters on Force Ripple and Force Density. In order to provide useful advice for application, the influence of major structural parameters on force ripple and force density should be analyzed in order to find a useful optimized method for future design process.

The major structural parameters are defined as the structural parameters which can determine the FVPMLVI's electromagnetic and mechanical characteristics. As shown in Figure 2, the major structural parameters include width of stator magnets $d_{s 1}$ and $d_{s 2}$, thickness of stator magnets $h_{s 1}$ and $h_{s 2}$, and width and thickness of mover magnets $d_{m}$ and $h_{m}$. The force ripple within unit displacement $\sigma$ and force density $\rho$ are calculated by (4) and (5), separately. 


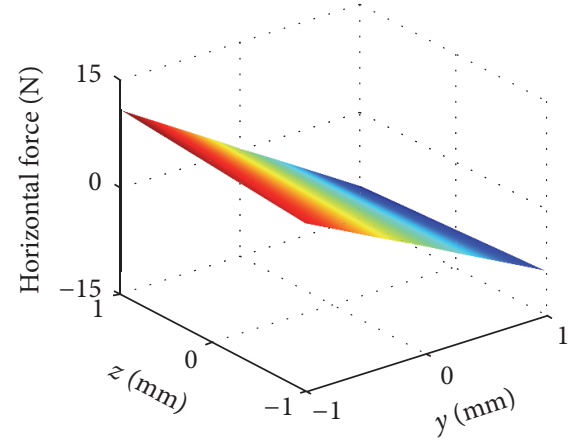

(a)

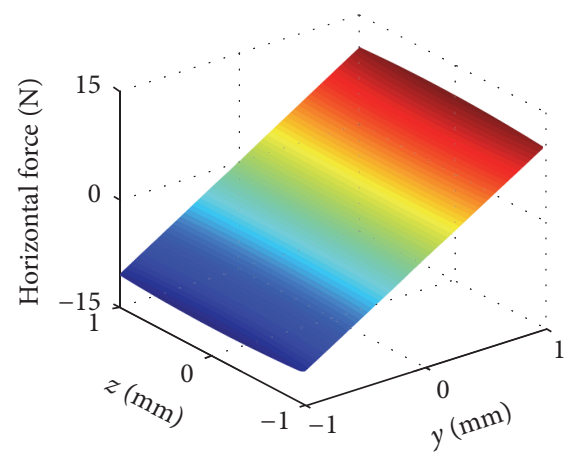

(b)

FIGURE 12: Horizontal force characteristics of two magnet arrays: (a) magnetic array D; (b) magnetic array E.

$$
\begin{aligned}
& \sigma=\frac{d F / F}{d s} \times 100 \% \\
& \rho=\frac{F}{V}=\frac{F}{\left[\left(4 d_{s 1}+2 d_{s 2}+4 t_{s}+2 t_{\text {ap }}\right) \times\left(2 h_{s 1}+2 h_{m}+2 \delta+t_{m}+2 t_{\text {ap }}\right) \times l_{\text {ap }}\right]},
\end{aligned}
$$

where $F$ is the levitation force of FVPMLVI, $V$ is the volume of FVPMLVI, $t_{s}$ is the spacing between stator magnets, $t_{\text {ap }}$ is the thickness of stator aluminum plates, $\delta$ is the thickness of air gap, $t_{m}$ is the spacing between mover magnets, and $l_{\text {ap }}$ is the length of FVPMLVI in $x$-axis.

The influence of major structural parameters on force ripple and force density is analyzed by finite element method. The major structural parameters are studied with some auxiliary structural parameters fixed; that is, the length of FVPMLVI in $x$-axis $l_{\text {ap }}$ is $100 \mathrm{~mm}$; the spacing between stator magnets $t_{s}$ and between mover magnets $t_{m}$ is $1 \mathrm{~mm}$ and $2 \mathrm{~mm}$, respectively. Considering the stroke and manufacturability, the air gap length $\delta$ is chosen to be $3 \mathrm{~mm}$.

Firstly, from Figures 8 and 9, the stiffness of levitation force generated by magnet array B is opposite to that of magnet array C. Thus, there is a reasonable range of $d_{s 1}$ and $d_{s 2}$, where the total stiffness of magnet array $\mathrm{B}$ and $\mathrm{C}$ is near-zero; then the force ripple can be decreased significantly. Simultaneously, the levitation force will increase when $d_{s 1}$ and $d_{s 2}$ are increased. However, from (5), the volume of PMLVI will also increase with the increase of $d_{s 1}$ and $d_{s 2}$, which brings a negative influence on the force density. Thus, there is a reasonable range of $d_{s 1}$ and $d_{s 2}$, where force density obtains the maximum.

The force ripple which varied with $d_{s 1}$ and $d_{s 2}$ is shown in Figure 13. From Figure 13, (1) the force ripple caused by vertical motion is decreased significantly when $d_{s 1}$ and $d_{s 2}$ take appropriate values; (2) the minimum of force ripple caused by vertical motion occurs when $d_{s 2}$ is in the range of $6.2 \mathrm{~mm} \sim 7.2 \mathrm{~mm}$; (3) the force ripple caused by horizontal motion is decreased significantly when $d_{s 1}$ and $d_{s 2}$ take appropriate values; (4) the minimum force ripple caused by vertical motion occurs when $d_{s 2}$ is in the range of $8.4 \mathrm{~mm} \sim$ $12.2 \mathrm{~mm}$.

The levitation force and force density which varied with $d_{s 1}$ and $d_{s 2}$ are is shown in Figure 14. From Figure 14, (1) the levitation force increases with the increase of $d_{s 1}$ and $d_{s 2} ;(2)$ the maximum of force density occurs when $d_{s 1}$ is in the range of $4 \mathrm{~mm} \sim 6 \mathrm{~mm}$, and $d_{s 2}$ is expected to be as small as possible. This shows that although force ripple is decreased by adopting special stator magnet array, the force density is also decreased.

Similar to the analysis of $d_{s 1}$ and $d_{s 2}$, there is a reasonable range of $h_{s 1}$ and $h_{s 2}$, where force ripple can be decreased significantly and force density reaches the maximum. It should be noted that $h_{s 1}$ is designed to be larger than $h_{s 2}$, because the air gap length is fixed, and a larger $h_{s 2}$ will lead to a shorter stroke. Through changing the thickness of stator magnets $h_{s 1}$ and $h_{s 2}$, the force ripple is calculated, as shown in Figure 15. From Figure 15, (1) the force ripple caused by vertical motion is decreased significantly when $d_{s 1}$ and $d_{s 2}$ take appropriate values; (2) the minimum of force ripple caused by vertical motion occurs when $h_{s 1}=$ $-0.1214 h_{s 2}^{2}+2.179 h_{s 2}+0.14$; (3) the force ripple caused by horizontal motion is decreased significantly when $h_{s 1}$ and $h_{s 2}$ take appropriate values; the minimum of force ripple caused by horizontal motion occurs when $h_{s 1}$ and $h_{s 2}$ are about $4 \mathrm{~mm}$ and $1 \mathrm{~mm}$, respectively.

The levitation force and force density which varied with $h_{s 1}$ and $h_{s 2}$ are is shown in Figure 16. From Figure 16, (1) the levitation force increases with the increase of $h_{s 1}$ and $h_{s 2}$; (2) the maximum of force density occurs when $h_{s 2}$ takes larger values and $h_{s 1}=h_{s 2}$; the force density can be further increased if $h_{s 2}$ takes values in a wider range; however, the force ripple will increase. 


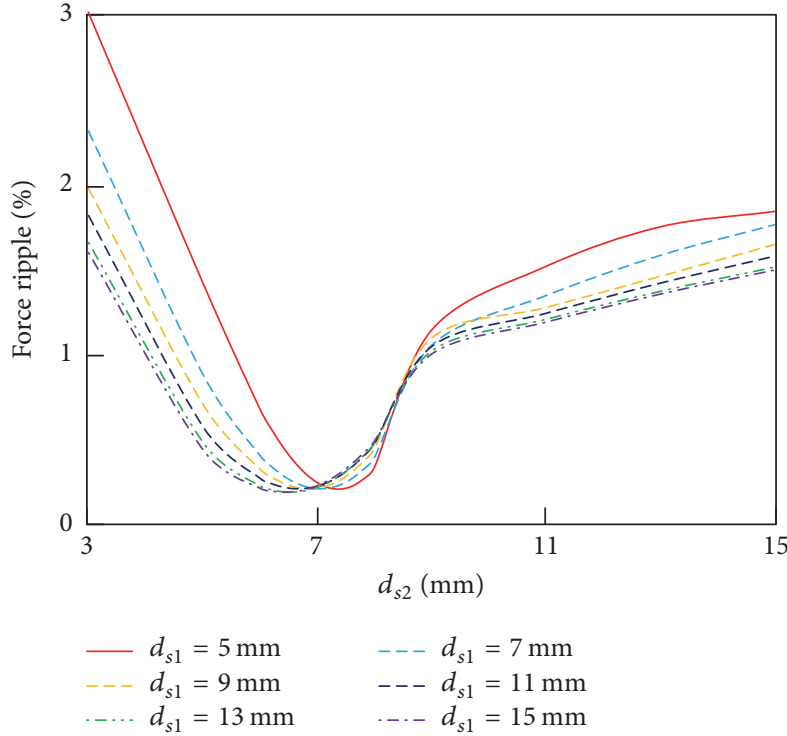

(a)

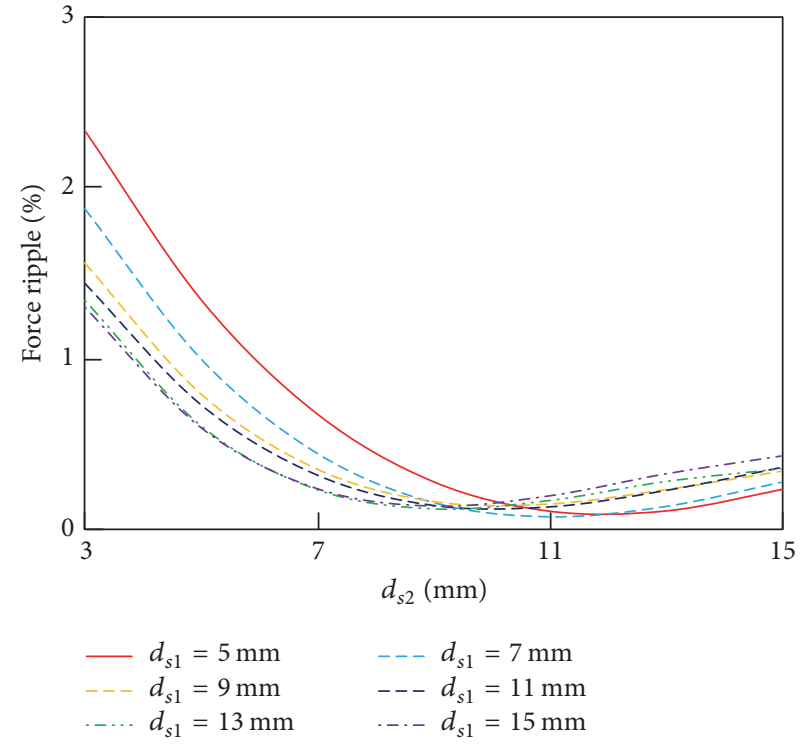

(b)

FIGURE 13: Force characteristics versus width of stator magnets $d_{s 1}$ and $d_{s 2}$ : (a) force ripple caused by vertical motion; (b) force ripple caused by horizontal motion.

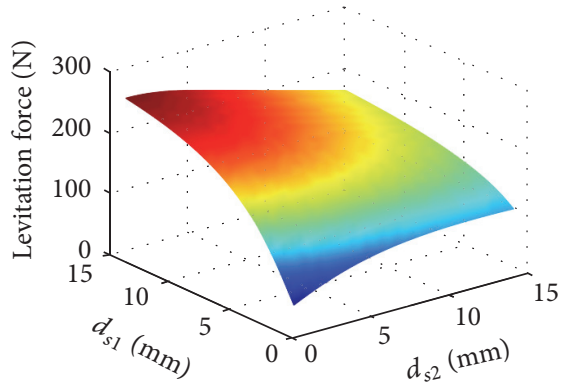

(a)

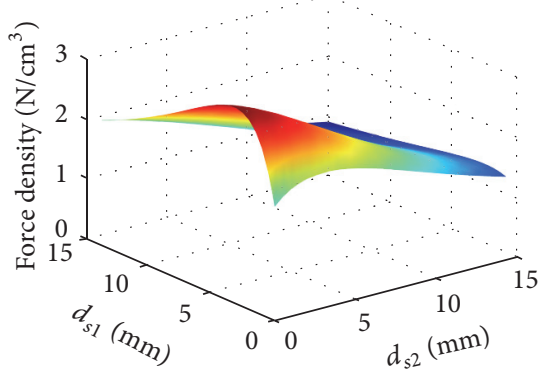

(b)

FIGURE 14: Force characteristics versus width of stator magnets $d_{s 1}$ and $d_{s 2}$ : (a) levitation force; (b) force density.

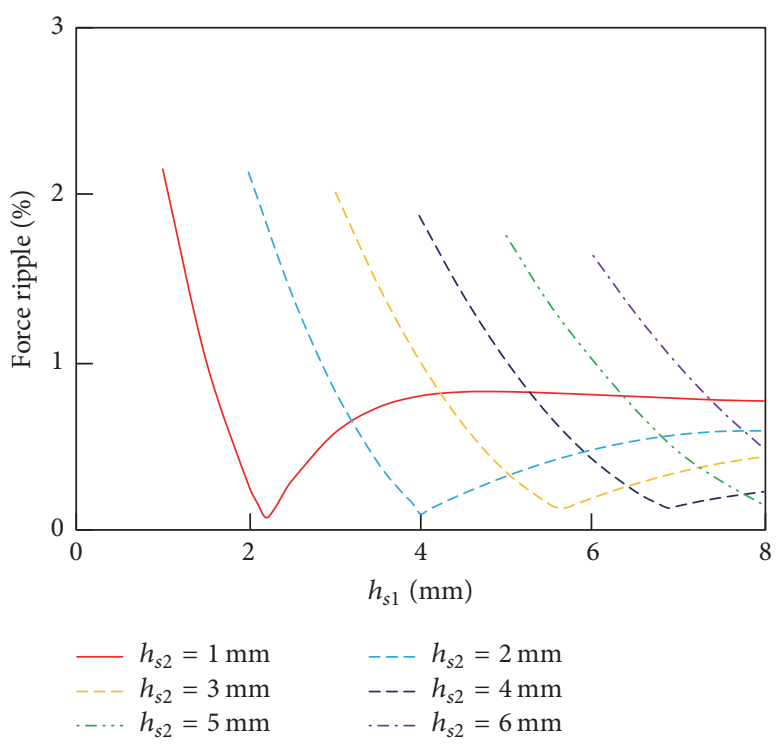

(a)

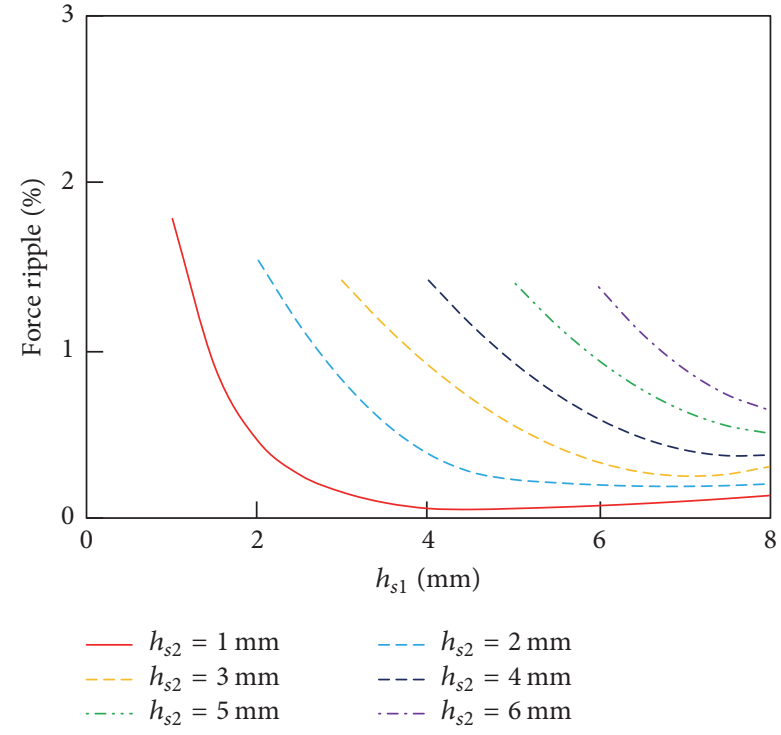

(b)

FIGURE 15: Force characteristics versus thickness of stator magnets $h_{s 1}$ and $h_{s 2}$ : (a) force ripple caused by vertical motion; (b) force ripple caused by horizontal motion. 


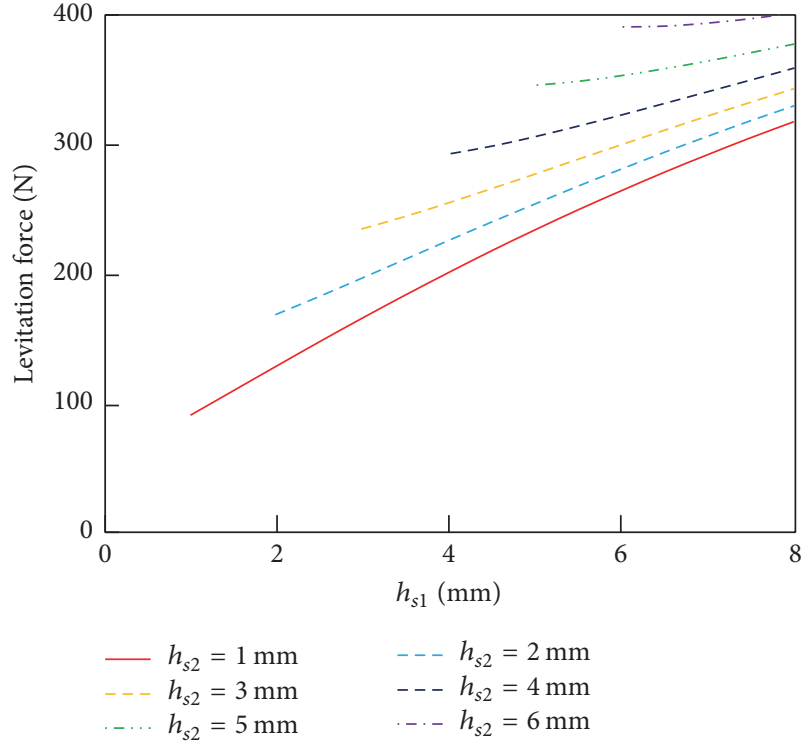

(a)

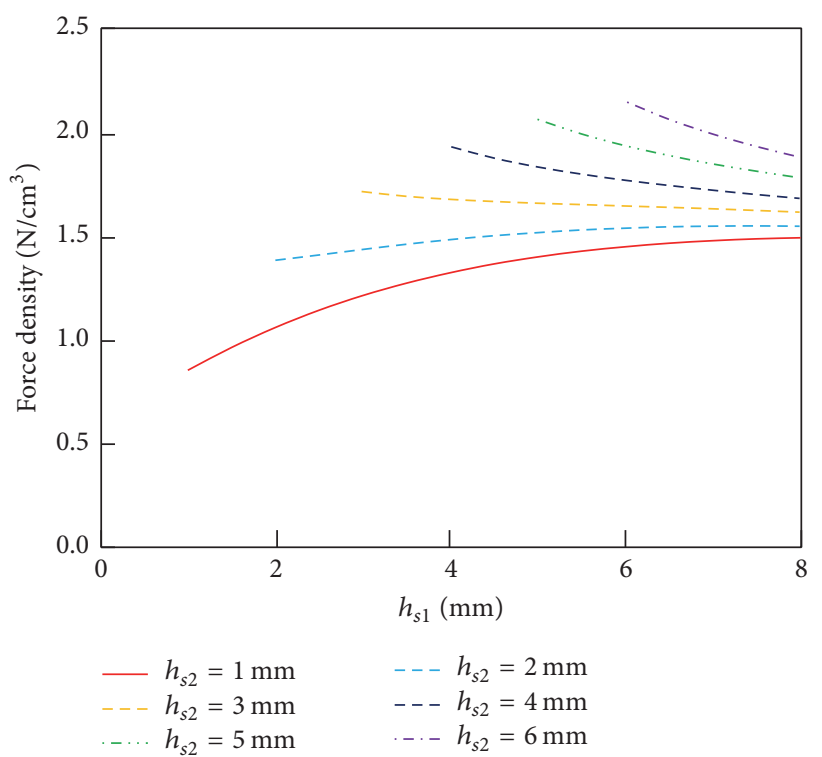

(b)

FIGURE 16: Force characteristics versus thickness of stator magnets $h_{s 1}$ and $h_{s 2}$ : (a) levitation force; (b) force density.

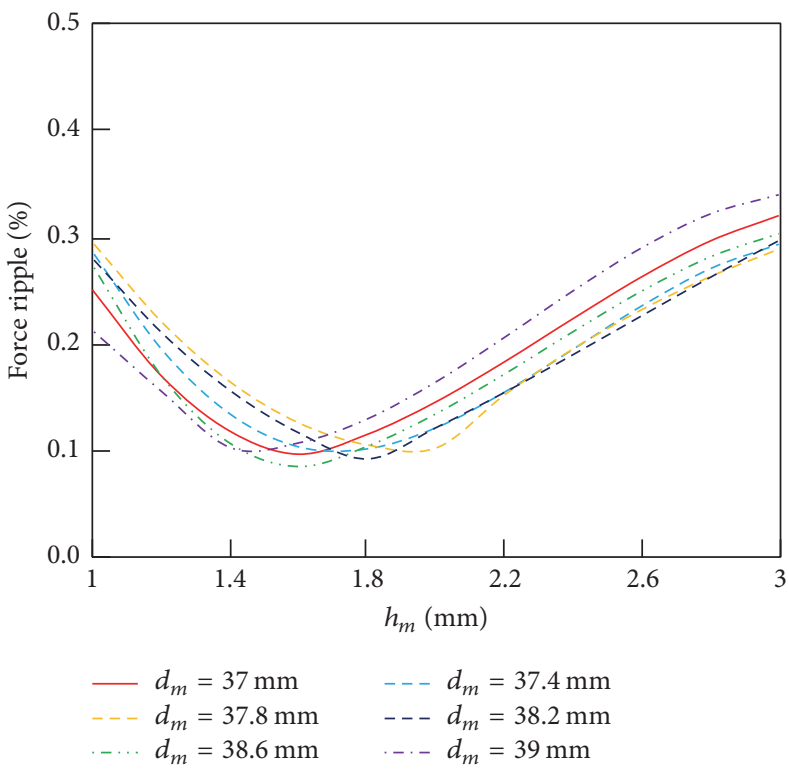

(a)

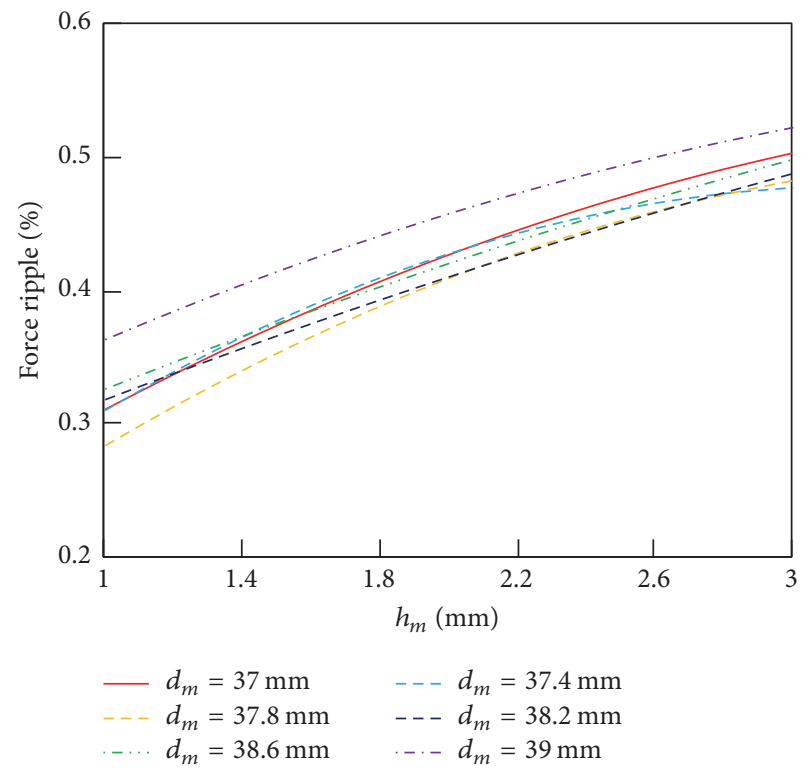

(b)

FIGURE 17: Force characteristics versus width and thickness of mover magnets $d_{m}$ and $h_{m}$ : (a) force ripple caused by vertical motion; (b) force ripple caused by horizontal motion.

The force characteristics of PMLVI could be also adjusted by the structural parameters of mover. Through changing the width and thickness of mover magnets $d_{m}$ and $h_{m}$ in a small range, the force ripple is calculated as shown in Figure 17. From Figure 17, (1) the force ripple caused by vertical motion is decreased significantly when $d_{m}$ and $h_{m}$ take appropriate values; the minimum of force ripple caused by vertical motion occurs when $h_{m}=-0.4138 d_{m}^{2}+31.33 d_{m}-591.1$; (3) the force ripple caused by horizontal motion is decreased significantly when $h_{m}$ decreases.
The levitation force and force density which varied with $d_{m}$ and $h_{m}$ are shown in Figure 18. From Figure 18, (1) the levitation force increases significantly with the increase of $h_{m}$; the levitation force is nearly proportional to the thickness of mover magnets $h_{m}$; (2) from (5), with the increase of $h_{m}$, the increase magnitude in levitation force is larger than the increase magnitude of its volume; thus the force density also increases significantly.

Based on the analysis results above, an optimized FVPMLVI is designed and analyzed by experiment. It should be 


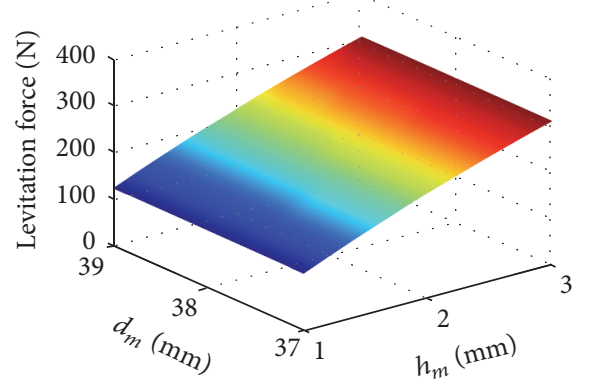

(a)

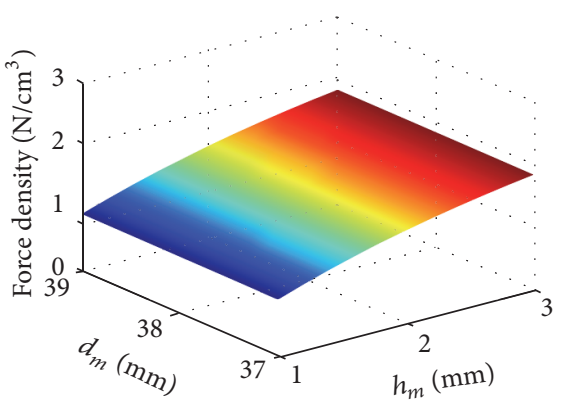

(b)

FIGURE 18: Force characteristics versus width and thickness of mover magnets $d_{m}$ and $h_{m}$ : (a) levitation force; (b) force density.

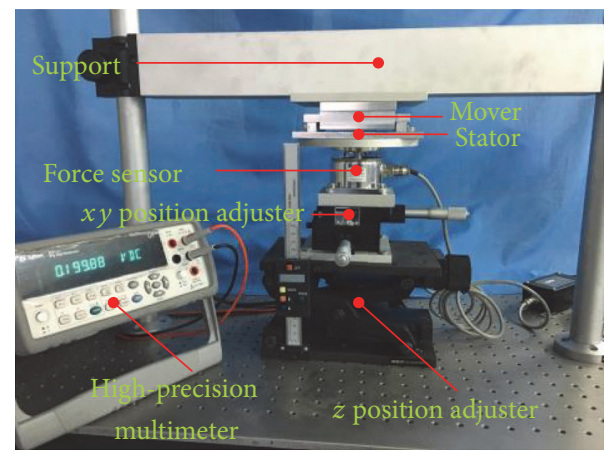

FIGURE 19: The test platform for measuring force characteristics of the FVPMLVI.

mentioned that the parameters of the optimized model in this section are preliminary optimization results based on the forgoing FEM analysis. A more accurate optimization result can be obtained by using some optimization methods in the design process, for example, numerical optimization algorithms or approximate models [16, 17].

4.3. Experiment. To verify the analysis presented above, a prototype of the FVPMLVI is manufactured. The structural parameters of prototype are listed in Table 1 . The test platform for measuring force characteristics of the FVPMLVI is shown in Figure 19. The test platform is composed of a three-degree of freedom position adjuster, a force sensor, a high-precision multimeter, and a support. The three-degree of freedom position adjuster is composed of a $x y$ position adjuster and a $z$ position adjuster. The three-degree of freedom position adjuster and the support are fixed on a passive vibration isolation platform separately, and the force sensor is fixed on the three-degree of freedom position adjuster. The mover of FVPMLVI is fixed on the support, and the stator of FVPMLVI is fixed on the force sensor. Therefore the relative position between stator and mover can be adjusted by the three-degree of freedom position adjuster. The relationship between force and mover position can be measured.

Figure 20 shows the levitation force distribution with different vertical displacement $(z)$ and horizontal displacement $(x$ and $y$ ). The measured nominal levitation force is
TABLE 1: Structural parameters of PMLVI prototype.

\begin{tabular}{lc}
\hline Parameter & Data \\
\hline Width of stator magnet $d_{s 1}$ & $15 \mathrm{~mm}$ \\
Thickness of stator magnet $h_{s 1}$ & $4 \mathrm{~mm}$ \\
Width of stator magnet $d_{s 2}$ & $6 \mathrm{~mm}$ \\
Thickness of stator magnet $h_{s 2}$ & $2 \mathrm{~mm}$ \\
Length of stator magnet $l_{s}$ & $108 \mathrm{~mm}$ \\
Stator magnet spacing $t_{s}$ & $1 \mathrm{~mm}$ \\
Width of mover magnet $d_{m}$ & $38.6 \mathrm{~mm}$ \\
Thickness of stator magnet $h_{m}$ & $1.6 \mathrm{~m}$ \\
Length of mover magnet $l_{m}$ & $100 \mathrm{~mm}$ \\
Mover magnet spacing $t_{m}$ & $2 \mathrm{~mm}$ \\
Length of air gap $\delta$ & $3 \mathrm{~mm}$ \\
Aluminum plate thickness $t_{\mathrm{ap}}$ & $4 \mathrm{~mm}$ \\
\hline
\end{tabular}

197.64 N, which matches well with the finite element model. The variation of the levitation force is quite small for the whole stroke.

The stiffness is obtained from the levitation force characteristics by using (6). Figure 21 shows the vertical stiffness distribution with different vertical displacement $(z)$ and horizontal displacement $(x$ and $y$ ). It can be seen that the vertical stiffness can be as low as zero in some areas. The maximum positive vertical stiffness is $1008.26 \mathrm{~N} / \mathrm{m}$, and the natural frequency near this point calculated by (3) is $1.13 \mathrm{~Hz}$. Compared with passive magnetic levitation vibration isolators with natural frequency more than $4 \mathrm{~Hz}[2,3,10-14]$, the proposed passive maglev vibration isolation unit features advantage in lower natural frequency.

$$
K_{z}=\frac{\partial F_{z}}{\partial z}
$$

\section{Conclusions}

A flat-type vertical-gap passive magnetic levitation vibration isolator has been investigated for active vibration isolation system. The dual-stator scheme and special stator magnet array can decrease FVPMLVI's natural frequency effectively, and this enhances the vibration isolation capability of the FVPMLVI. The magnets used in FVPMLVI are parallel 


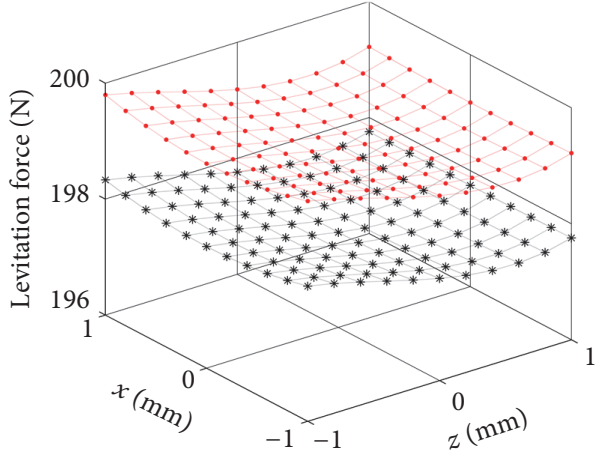

- Finite element method * Experiment

(a)

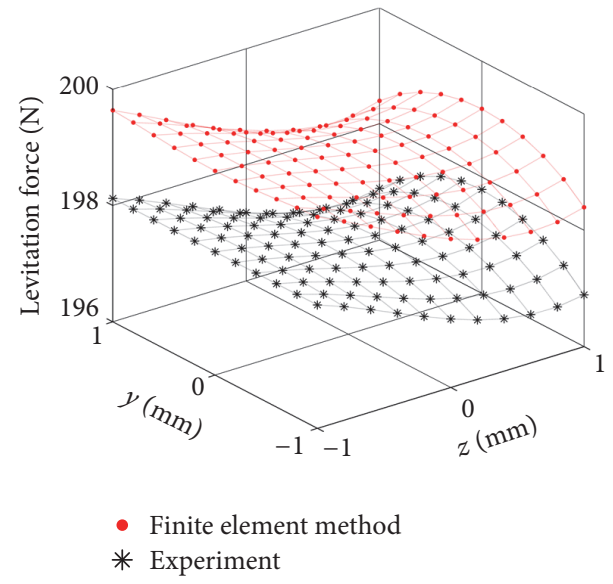

(b)

FIgURE 20: The levitation force characteristics of FVPMLVI.

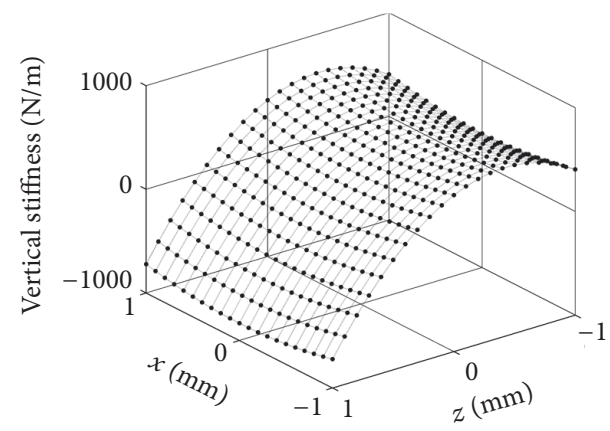

(a)

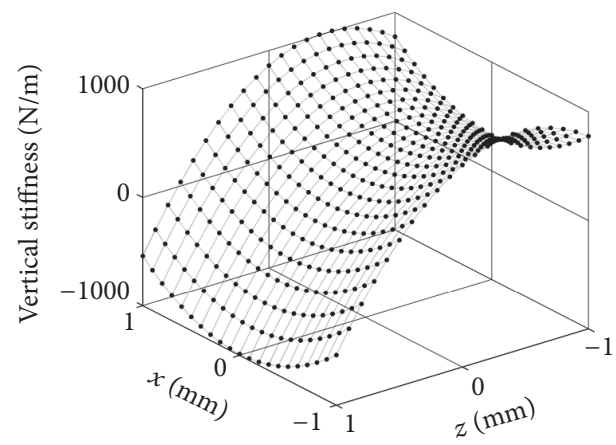

(b)

FIgURE 21: The stiffness characteristics of FVPMLVI.

magnetized cubic magnets, which have advantages of simple structure, good manufacturability, and low cost. The analytical expression of magnetic force is deduced by equivalent charge model. The influence of major structural parameters and motion on levitation force, horizontal force, force density, and force ripple are studied. The dimensions of both stator magnets and mover magnets have significant impact on levitation force, horizontal force, force density, and force ripple. In comparison with conventional passive magnetic levitation vibration isolators, the proposed flat-type vertical-gap passive magnetic levitation vibration isolator shows advantage in lower natural frequency, wider vibration isolation bandwidth, and lower vibration transmissibility.

\section{Competing Interests}

The authors declare that there are no competing interests regarding the publication of this paper.

\section{Acknowledgments}

This research is supported by the National Natural Science Foundation of China (51507034).

\section{References}

[1] R. H. Stulen and D. W. Sweeney, "Extreme ultraviolet lithography," IEEE Journal of Quantum Electronics, vol. 35, no. 5, pp. 694-699, 1999.

[2] E. Puppin and V. Fratello, "Vibration isolation with magnet springs," Review of Scientific Instruments, vol. 73, no. 11, p. 4034, 2002.

[3] Y. Zhu, Q. Li, D. Xu, and M. Zhang, "Modeling of axial magnetic force and stiffness of ring-shaped permanent-magnet passive vibration isolator and its vibration isolating experiment," IEEE Transactions on Magnetics, vol. 48, no. 7, pp. 2228-2238, 2012.

[4] W. Robertson, B. Cazzolato, and A. Zander, "A multipole array magnetic spring," IEEE Transactions on Magnetics, vol. 41, no. 10, pp. 3826-3828, 2005.

[5] W. S. Robertson, M. R. F. Kidner, B. S. Cazzolato, and A. C. Zander, "Theoretical design parameters for a quasi-zero stiffness magnetic spring for vibration isolation," Journal of Sound and Vibration, vol. 326, no. 1-2, pp. 88-103, 2009.

[6] W. Robertson, B. Cazzolato, and A. Zander, "Theoretical analysis of a non-contact spring with inclined permanent magnets for load-independent resonance frequency," Journal of Sound and Vibration, vol. 331, no. 6, pp. 1331-1341, 2012. 
[7] J. L. G. Janssen, J. J. H. Paulides, E. A. Lomonova, B. Delinchant, and J.-P. Yonnet, "Design study on a magnetic gravity compensator with unequal magnet arrays," Mechatronics, vol. 23, no. 2, pp. 197-203, 2013.

[8] D. T. E. H. van Casteren, J. J. H. Paulides, J. L. G. Janssen, and E. A. Lomonova, "Analytical force, stiffness, and resonance frequency calculations of a magnetic vibration isolator for a microbalance," IEEE Transactions on Industry Applications, vol. 51, no. 1, pp. 204-210, 2015.

[9] D. T. E. H. van Casteren, J. J. H. Paulides, and E. A. Lomonova, "A comparison between cylindrical and cross-shaped magnetic vibration isolators: ideal and practical," Archives of Electrical Engineering, vol. 64, no. 4, pp. 593-604, 2015.

[10] Y. Zhu, Q. Li, D. Xu, C. Hu, and M. Zhang, "Modeling and analysis of a negative stiffness magnetic suspension vibration isolator with experimental investigations," Review of Scientific Instruments, vol. 83, no. 9, Article ID 095108, 2012.

[11] D. Xu, Q. Yu, J. Zhou, and S. R. Bishop, "Theoretical and experimental analyses of a nonlinear magnetic vibration isolator with quasi-zero-stiffness characteristic," Journal of Sound and Vibration, vol. 332, no. 14, pp. 3377-3389, 2013.

[12] W. Wu, X. Chen, and Y. Shan, "Analysis and experiment of a vibration isolator using a novel magnetic spring with negative stiffness," Journal of Sound and Vibration, vol. 333, no. 13, pp. 2958-2970, 2014.

[13] K. Shin, "On the performance of a single degree-of-freedom high-static-low-dynamic stiffness magnetic vibration isolator," International Journal of Precision Engineering and Manufacturing, vol. 15, no. 3, pp. 439-445, 2014.

[14] Y. Zheng, X. Zhang, Y. Luo, B. Yan, and C. Ma, "Design and experiment of a high-static-low-dynamic stiffness isolator using a negative stiffness magnetic spring," Journal of Sound and Vibration, vol. 360, pp. 31-52, 2016.

[15] H. Allag, J.-P. Yonnet, and M. E. H. Latreche, "3D analytical calculation of forces between linear halbach-type permanentmagnet arrays," in Proceedings of the 8th International Symposium on Advanced Electromechanical Motion Systems and Electric Drives Joint Symposium (ELECTROMOTION '09), July 2009.

[16] G. Lei, T. Wang, Y. Guo, J. Zhu, and S. Wang, "System-level design optimization methods for electrical drive systems: deterministic approach," IEEE Transactions on Industrial Electronics, vol. 61, no. 12, pp. 6591-6602, 2014.

[17] G. Lei, T. Wang, J. Zhu, Y. Guo, and S. Wang, "Systemlevel design optimization method for electrical drive systemsrobust approach," IEEE Transactions on Industrial Electronics, vol. 62, no. 8, pp. 4702-4713, 2015. 


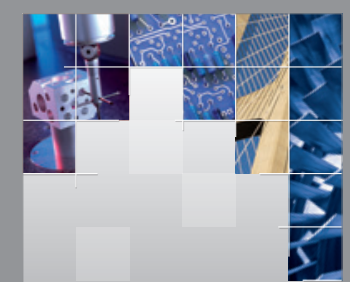

\section{Enfincering}
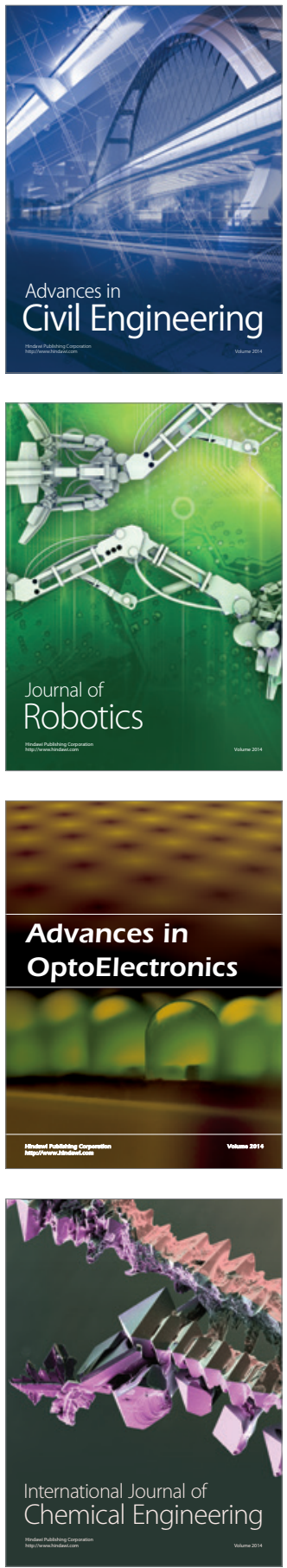

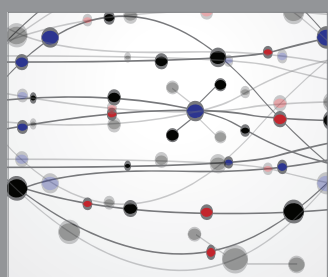

The Scientific World Journal

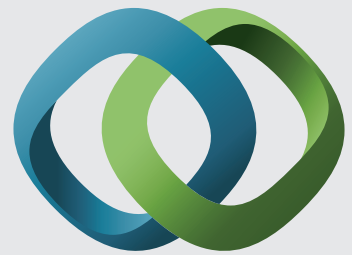

\section{Hindawi}

Submit your manuscripts at

http://www.hindawi.com
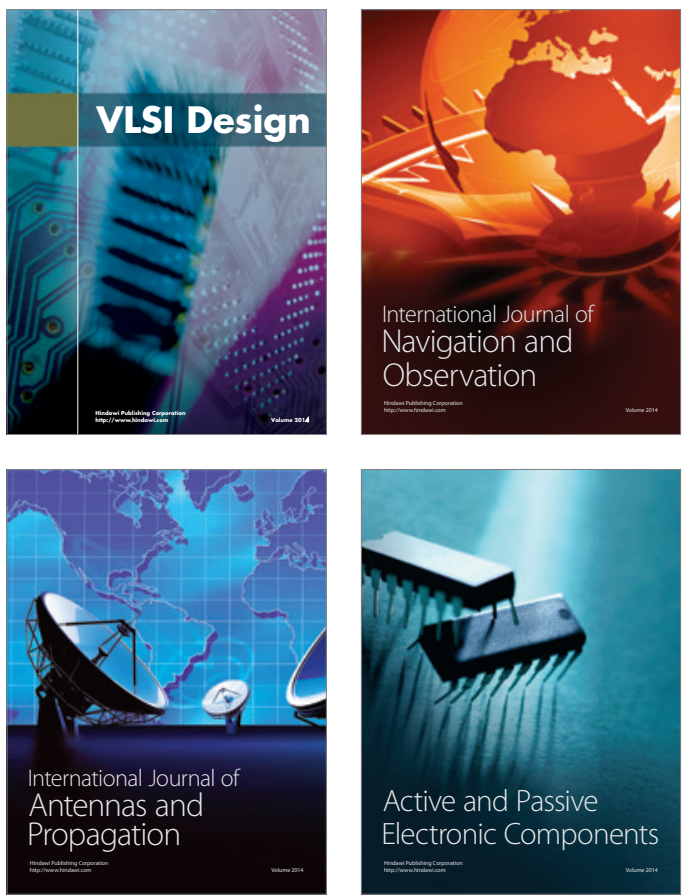
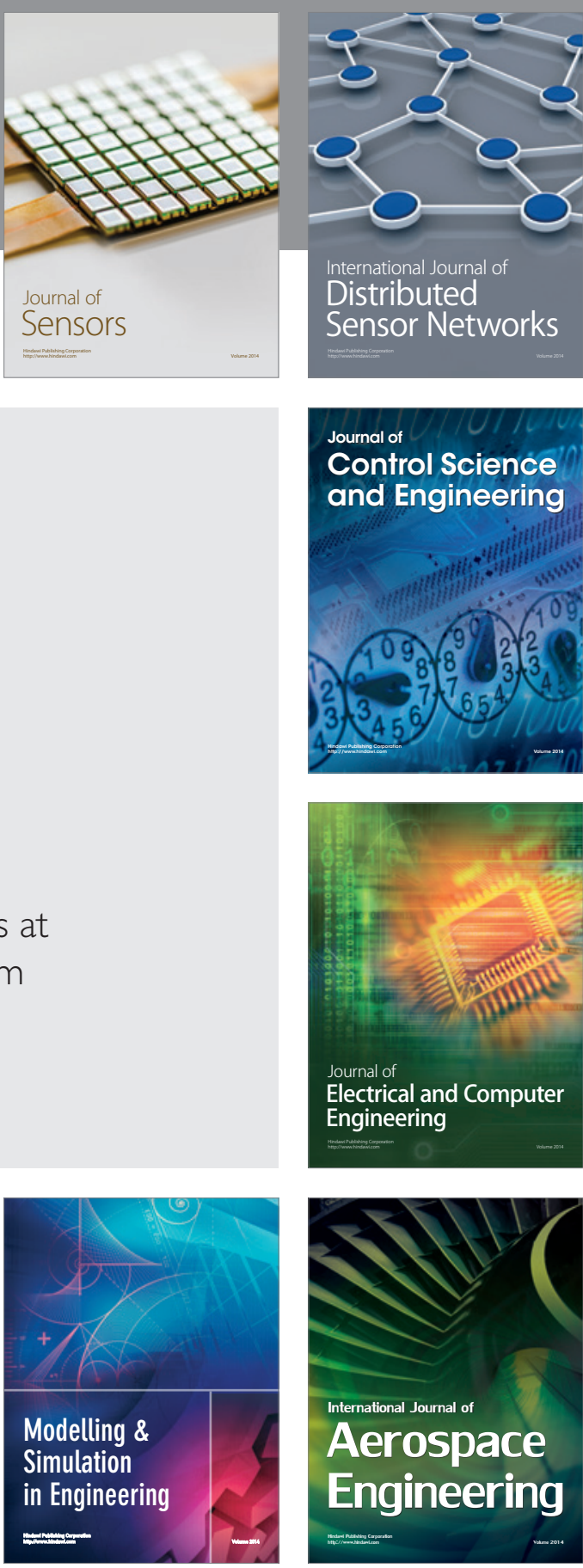

International Journal of

Distributed

Sensor Networks

Journal of

Control Science

and Engineering
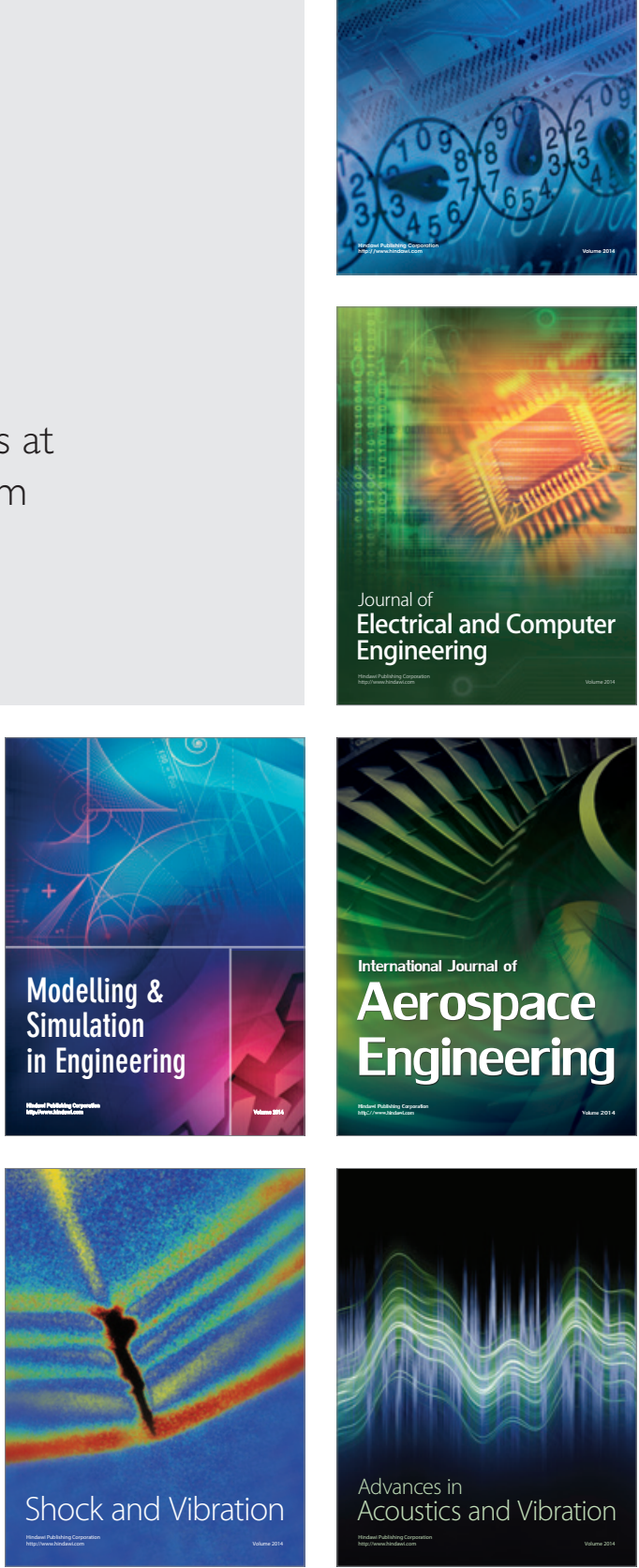